\title{
Robert Brown and the Cell Theory
}

THE Linnean Society has issued as an extract from its Proceedings (1931-32, pt. 2) the series of addresses delivered at the general meeting on Nov. 19, 1931, which took the form of the centenary celebration of Robert Brown's discovery of the nucleus of the vegetable cell. The brochure contains an account, by Mr. J. Ramsbottom, of Brown's life and botanical work, one by Mr. S. Savage of his connexion with the Linnean Society, the passage from the memoir containing Brown's account of his discovery, and an address by Lieut.-Col. J. Stephenson on Brown's discovery in relation to the history of the cell theory.

The discovery was announced at the close of a paper "On the Organs and Mode of Fecundation in Orchideæ and Asclepiadeæ " read at the meetings of the Society on Nov. 1 and 15, 1831. The paper was afterwards printed in the Society's Transactions.

It was characteristic of Brown to refer incidentally in communications the main purport of which was taxonomic, to discoveries of fundamental importance. In 1809, in a monograph on the Proteaceæ, which he had studied in Australia, he indicates the true relation between endosperm and embryo in the seed. In 1825 , to a description of the remarkable Australian Juncaceous tree, Kingia, he adds his observations on the structure of the ovule and female flower in the Cycads and Conifers, which established the distinction between the Gymnospermous and Angiospermous flowering plants. To Brown also is owed the recognition of the Brownian movement of small particles (1827), and of the streaming of protoplasm, which latter he observed in the staminal hairs of Tradescantia (1831) many years before the 'discovery' of protoplasm.

Brown described the nucleus as a more or less distinctly granular areola, generally somewhat more opaque than the cell membrane, to which it sometimes adheres, projecting into the cell cavity, but it is not infrequently central or nearly so. It was observed in several families of Monocotyledons and Dicotyledons. Brown was the essence of caution, but the remark of Prof. F. E. Weiss, after reading the extract from the memoir, that Brown was inclined to regard the nucleus as an attribute of all vegetable cells, is justifiable.

Lieut.-Col. Stephenson pointed out that in 1831 we have already no inconsiderable part of that body of doctrine that goes by the name of the 'cell theory'. It is incomplete, in that it has scarcely as yet been applied to animals, no account of the origin of cells has been given, and the emphasis is mainty on the cell wall. Between 1831 and 1838, through the activities of the Breslau school under Purkinje and the rival Berlin school led by Joh. Müller, cells had been described in all the chief tissues of the animal body; the production of new cells by division had been seen by Dumortier and other botanists, nucleus and nucleolus had been recognised, and animal and plant cells appreciated as equivalent structures. Purkinje had noted the absence of a special membrane in animal cells.

The cell theory was therefore practically established by the year 1838, and Lieut.-Col. Stephenson protested vigorously against the general use in lectures and textbooks of the phrase "the Cell-Theory of Schleiden and Schwann". He insisted that Schleiden's erroneous theory of endogenous cell formation, accepted by his pupil Schwann, was a distinctly retrograde movement. Schwann also conceived the erroneous idea of the origin of new cells in the intercellular substance; and his mode of comparison of the plant and animal cell tended to accentuate and to perpetuate the view of the cell wall as the chief and distinctive character of the cell. Schwann's "Microscopical Researches " was published in 1839 . In 1850, Braun expressed the opinion that the cell was, properly speaking, the substance within the membrane; but it was 1861 before Max Schultze defined a cell simply as a particle of protoplasm containing a nucleus. Therewith Brown may be said finally to have come into his own. Among the builders of the cell theory he holds an honourable place.

\section{The Value of 'Protective' Adaptations of Animals}

$\mathrm{O}^{\mathrm{NE}}$ of the hypotheses on which the theory of natural selection is based consists in the interpretation of the coloration and general appearance of animals from the point of view of protection from enemies. The range of "protective" devices considered to be sufficiently effective as factors in the selection is very great, but exact investigations aiming at proving that such devices actually protect their possessors are scarce.

Selectionists assume a discrimination in the choice of prey on the part of predators, and one of the methods by which the existence of such a discrimination can be tested obviously consists in studies on the food of predators, by analysing the contents of their stomachs. Results of the studies, however, can only be convincing if the series of records are sufficiently long to eliminate the accidental and to arrive at statistically sound conclusions. In this respect, the investigations on the contents of birds' stomachs undertaken by the U.S. Bureau of Biological Survey* are beyond reproach, for they cover a period of more than forty years (since 1885), during which about

* Smithsonian Miscellaneous Collections, vol. 85, No. 7, "Effectiveness in Nature of the so-called Protective Adaptations in the Animal Kingdom, chiefly as illustrated by the Food Habits of Nearetic Birds", By W. L. McAtee. Pp. 201. (Washington, D.C. : Smithsonian Institution, 1932.)

No. 3271, Vor. 130]
80,000 birds have been examined and as many as 237,399 identifications of animals found in their stomachs made. A common objection to this method is that anything found in a bird's stomach would be in an unrecognisable state. This, however, proved to be a misconception, since most birds swallow their food whole, and even in the cases of the most fragile insects, such as butterflies, certain parts, for example, wing scales, are perfectly well preserved, so that an approximate identification is possible.

The first conclusion arising out of the accumulated data is that the animals serving as food for birds belong to all the systematic groups of the animal kingdom from Protozoa to mammals. Within the size limits, animals of practically every kind accessible to birds are preyed upon, so that no groups can be considered immune from their attacks. Still more significant is the conclusion, supported by abundant statistical data, that the number of captures from each group is in proportion to the abundance of animals of that group. The figures for insects are particularly striking. Records for Rhynchota, for example, constitute about 11 per cent of all records of insects found in the stomachs of birds, and the percentage of known species of Rhynchota in relation to all known insects is about 8 per cent ; the respective 
figures for Lepidoptera are 9 and 15 per cent; for Coleoptera, 44 and 46 per cent; for Hymenoptera, 14 and 17 per cent; and so on. This means that various animals are captured by birds approximately in proportion to their numbers, and no selective discrimination between groups on the part of birds is apparent. In other words, the predation takes place in much the same way as if there were no such thing as protective adaptation.

As regards various devices interpreted by selectionists as protective, their value can be gauged by the relative abundance of animals with such devices in birds' stomachs. The data in this respect are very discouraging to selectionists. It is not surprising, of course, that animals with coloration harmonising with their surroundings are eaten freely, since this can be interpreted as the selection in action. Much more important is the fact that animals presumably protected by poisonous secretions are also consumed in proportion to their numbers and, therefore, cannot be said to enjoy any protection. A beetle, Macrodactylus, is definitely poisonous and many young birds are killed by eating it, but it is, nevertheless, eaten freely, and the advantage of being poisonous is not obvious. Again, all spiders are venomous, but the 10,000 records of spiders having been eaten by more than 300 species of birds emphasise the complete disregard by birds of this method of protection. All the members of the group of Rhynchota (bugs) are always regarded by selectionists as being specially well protected by their taste or unpleasant smell. The fallacy of this statement is made clear by the 22,395 records of Rhynchota found in stomachs, the percentage of the records being in close agreement with the relative abundance of these insects.

Bright and contrasting colours of insects are usually considered as "warning', and the Coccinellid beetles, or ladybirds, represent a classical example of ' warning coloration', possibly developed by selection and serving to advertise their unpalatability. There are, however, 1455 records of Coccinellids found in the stomachs of 127 species of birds; since up to 15 insects have been found in one stomach, their " warning' coloration and the inedibility must be a fiction. Another equally well-known example of a specially protected group of insects is represented by the ants, and their immunity from attacks is said to be so great that many other arthropods secure protection from enemies by mimicking ants. The 12,000 records of ants eaten by well over 300 species of birds make the status of ants as a protected group untenable. Some birds eat ants in very large numbers, and up to 2000 ants have been found in one stomach. It is particularly noteworthy that even ants of the family Myrmicidæ, notorious for their stinging habit, are not avoided, as is shown by 1200 records of their presence in stomachs, containing in some cases up to 400 individuals. Wasps are considered also as regular models for mimicry, being themselves presumably well protected by sting and also 'warningly' coloured, but 140 species of birds eat them, up to 30 wasps at a meal.

The whole book is full of examples of this kind, most carefully collected and thoroughly analysed, and represents an array of arguments of which selectionists will find it very difficult to dispose. The principle of proportional predation is exhibited so clearly and forcefully that a discrimination in the choice of prey by birds (and other vertebrates, also considered in the paper) is shown to be simply non-existent. Indeed, the data at hand denote a complete indiscrimination, the very antithesis of selection, and the phenomena classed by theorists as protective adaptations are shown to bear no relation to the survival of the fittest.
B. P. U.

\section{Aluminium in Foodstuffs}

$\mathrm{T}^{\mathrm{H}}$ HE meeting of the Society of Public Analysts on June 1 was devoted to papers on the effects and estimation of aluminium in foodstuff.

A survey of the physiological effects of aluminium was given by Dr. J. H. Burn. He said that the first extensive investigation of the physiological effects of aluminium salts was made in 1886 by Siem, working under Prof. H. H. Meyer. Siem found that doses corresponding with 30-40 grains of alumina for a man had no effect whatever when administered by mouth to cats daily for four weeks. When the aluminium salt was injected under the skin, the fatal dose varied from 0.25 to $0.30 \mathrm{gm}$. of alumina per kilogram. These results, indicating that aluminium has some toxicity when injected, but is harmless by mouth, have in substance been confirmed by many subsequent workers.

Siebert and Wells examined the pathological changes produced by injecting alum and aluminium chloride; they found that anæmia was manifested after nine or ten daily injections, a fall in the hæmoglobin percentage and in the red cell count being recorded. In the spleen, pigmentation, thrombosis, and fibrosis were observed.

The experiments of McCollum and his colleagues, and those of Myers and Mull, show conclusively that the addition of aluminium salts to the diet of young rats has no ill effect on growth, health, and reproduction, even when four successive generations are observed. The experiments of Myers and Morrison, and of Underhill and Peterman, show that when aluminium compounds are given by mouth to dogs, only insignificant changes in the amounts of aluminium in different tissues are found. It follows that alu- minium salts are not absorbed from the alimentary tract, except in traces.

As a result of a scare in the United States that the use of aluminium baking powders was dangerous to health, the Department of Agriculture instituted a board of inquiry. The report, published in 1914, described experiments on twenty-six university students carried out in three different universities, who were given amounts of alum varying from $0 \cdot 2$ gm. to $10 \mathrm{gm}$. daily for about six months. It was unanimously reported from the results of these experiments that the amounts of alum likely to be consumed as a result of alum in baking powder, estimated as up to $\mathbf{1} \cdot \mathbf{1 6}$ grain of aluminium per person per day, are much too small to have any ill effect. The amounts of aluminium which arise from aluminium vessels were estimated from analyses carried out by Massatch to be about $0 \cdot 1$ grain per person daily.

Indeed, the possible dangers arising from aluminium utensils have been very thoroughly investigated by many workers, on many species of animals; they have also been investigated with equal thoroughness on man. These dangers are non-existent. Clinical reports that symptoms of abdominal pain are relieved by discontinuing the use of aluminium can be ascribed to psychological effects.

Dr. L. H. Lampitt and Mr. N. D. Sylvester outlined a method for the accurate determination of small amounts of aluminium in foodstuffs, in which the Aurin tricarboxylic acid lake is formed under standardised conditions, the red colour of the final solution being measured in the Lovibond tintometer. Separation of aluminium from the 'wet ash' of the foodstuff is effected by a preliminary precipitation 